\title{
Systematic review of clinical and economic effectiveness of vildagliptin in type 2 diabetic patients with poor glycemic control on monotherapy with metformin
}

\author{
${ }^{1}$ Kazakh Agency for Health Technology Assessment, \\ Astana, Republic of Kazakhstan \\ 2Internal Diseases Clinic, S.D. Asfendiyarov Kazakh \\ National Medical University, Almaty, Republic of \\ Kazakhstan \\ ${ }^{3}$ National Center of Rational Clinical Practice, Astana, \\ Republic of Kazakhstan
}

Alima Almadiyeva ${ }^{1}$, Zhanay Akanov ${ }^{2}$, Venera Almatova ${ }^{3}$, Karlygash Absattarova

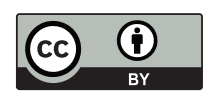

This work is licensed under a Creative Commons Attribution 4.0 International License

Received: 2018-10-26

Accepted: 2018-09-22

UDC: 616-08-039.73:616-036.8

\section{J Clin Med Kaz 2018;4(50):34-39}

Corresponding Author: Karlygash Absattarova, Kazakh Agency for Health Technology Assessment, Astana,

Republic of Kazakhstan.

E-mail: karlygash_absatt@mail.ru
Abstract

Aim: A study was conducted to assess the clinical and economic effectiveness of vildagliptin in adults with type 2 diabetes mellitus (T2DM) with poor glycemic control against the metformin monotherapy.

Materials and methods: 280 sources were identified in accordance with the search strategy; 40 sources were subjected to critical analysis, of which 22 full-text publications were included in the present study.

Results and discussion: Significant advantages of the use of vildagliptin in combination with metformin in improving glycemic control, regardless of the initial level of glycosylated hemoglobin (HbAlc), age or body mass index (BMI) compared with other dipeptidyl peptidase- 4 inhibitors, were found; Combination therapy using $50 \mathrm{mg}$ of vildagliptin and metformin twice daily significantly reduced the mean baseline $\mathrm{HbA} 1 \mathrm{c}(-0.7$ to $-0.9 \%)$ and fasting blood glucose levels $(-1.4$ to $0.1 \mathrm{mmol} / \mathrm{l})$ compared with placebo, as well as with other dipeptidyl peptidase- 4 inhibitors; this combination also led to the greatest increase in QALYs (0.18 over the life span) among dipeptidyl peptidase-4 inhibitors compared to treatment with a combination of metformin and glimepiride. Thus, the combination of metformin and vildagliptin gives advantages in efficiency and additional mechanisms of action, since it does not increase the risk of hypoglycemia and does not contribute to weight gain.

Conclusion: Combination therapy using metmorfin and vildagliptin is more cost-effective, since it does not increase the risk of hypoglycemia and does not lead to increasing weight.

Keywords: type 2 diabetes mellitus (T2DM), dipeptidyl peptidase-4 inhibitors, efficacy, safety

\section{МЕТФОРМИНМЕН МОНОТЕРАПИЯ АЯСЫНДА ГЛИКЕМИЯЛЫҚ ҚАНАҒАТТАНҒЫСЫЗ БАҚЫЛАУ КЕЗІНДЕ 2 ТИПТІ ҚАНТ ДИАБЕТІ БАР ЕРЕСЕК ЕМДЕЛУШІЛЕРДЕ ВИЛДАГЛИПТИНДІ ҚОЛДАНУДЫҢ КЛИНИКАЛЫҚ- ЭКОНОМИКАЛЫҚ ТИІМДІЛІГІНЕ ЖУЙЕЛІ ШОЛУ}

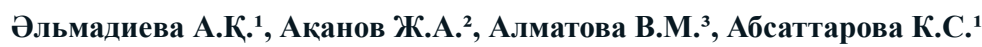

${ }^{1}$ Қазақстан Республикасының денсаулық сақтау технологияларын бағалау агенттігі, Астана, Қазақстан Республикасы

${ }^{2}$ Ішкі аурулар клиникасы, С.Д. Асфендияров атындағы Қазақ ұлттық медицина университеті, Алматы, Қазақстан Республикасы

з Ұлттық ұтымды клиникалық тәжірибе орталығы, Астана, Қазақстан Республикасы

\section{ТҰЖЫРЫМДАМА}

Мақсаты: Метформинмен монотерапия аясында қанағаттанғысыз гликемиялық бақылау кезінде 2 типті қант диабеті (2ТқД) бар ересек емделушілерде вилдаглиптиннің клиникалық және экономикалық тиімділігін бағалау мақсатында зерттеу жүргізілді.

Материалдар мен әдістер: іздеу стратегиясына сәйкес 280 әдеби көз анықталды, оның арасынан талдауға 40 әдеби көз тартылды, оның ішінде 22 толық мәтінді басылым осы зерттеуге енгізілген.

Нәтижелер мен талқылау: Гликозилденген гемоглобиннің (НbA1c) бастапқы деңгейіне, жасына немесе дене салмағының индексіне (ДСИ) тәуелсіз гликемиялық бақылауды жақсартуда метформинмен біріктіріп вилдаглиптинді қолданудың нақты маңызды артықшылықтары басқа 4-дипептидилпептидаза тежегіштерге қарағанда анықталған; 50 мг вилдаглиптин мен метформинді пайдаланып біріктірілген терапия күніне екі рет плацебомен, сондай-ақ басқа да 4-дипептидилпептидазы тежегіштерімен салыстырғанда аш қарынға қан глюкозасының 
(0,1 ммоль/л қарсы -1,4) деңгейін елеулі түрде төмендетті; сондай-ақ осы комбинация метформин мен глимепирид комбинациясымен салыстырғанда және басқа 4-дипептидилпептидазы тежегіштер арасында QALYs (өмір сүру ұзақтығы бойы - 0,18) ең көп өсуіне әкелді.

Қорытынды: Метморфин мен вильдаглиптинді біріктірілген түрде пайдалану кезде емнің тиімділігі мен қосымша әсер ету механизмдерінде артықшылықтары бар, өйткені осы қоспа гипогликемияның даму қаупін жоғарылатпайды және дене салмағының ұлғаюына әкелмейді.

Негізгі сөздер: 2 типті қант диабеті (2ТҚД), 4-дипептидилпептидаза тежегіштері, тиімділік, қауіпсіздік

\section{СИСТЕМАТИЧЕСКИЙ ОБЗОР КЛИНИКО-ЭКОНОМИЧЕСКОЙ ЭФФЕКТИВНОСТИ ПРИМЕНЕНИЯ ВИЛДАГЛИПТИНА У ВЗРОСЛЫХ ПАЦИЕНТОВ С САХАРНЫМ ДИАБЕТОМ 2 ТИПА ПРИ НЕУДОВЛЕТВОРИТЕЛЬНОМ ГЛИКЕМИЧЕСКОМ КОНТРОЛЕ НА ФОНЕ МОНОТЕРАПИИ МЕТФОРМИНОМ}

Альмадиева А.К. ${ }^{1}$, Аканов Ж.А. ${ }^{2}$, Алматова В.М. ${ }^{3}$, Абсаттарова К.С. ${ }^{1}$

${ }^{1}$ Казахстанское агентство по оценке технологий здравоохранения, Астана, Республика Казахстан

${ }^{2}$ Клиника внутренних болезней, Казахский национальный медицинский университет им. С.Д. Асфендиярова, Алматы, Республика Казахстан

${ }^{3}$ Национальный центр рациональной клинической практики, Астана, Республика Казахстан

\section{РЕЗЮМЕ}

Цель: Оценка клинической и экономической эффективности вилдаглиптина у взрослых пациентов с сахарным диабетом 2 типа (СД2Т) при неудовлетворительном гликемическом контроле на фоне монотерапии метформином.

Материалы и методы: В соответствии со стратегией поиска обнаружены 280 источников, из которых 40 литературных источников подверглись критическому анализу, в результате 22 полнотекстовых публикаций были включены в настоящее исследование.

Результаты и обсуждение: Обнаружены достоверно значимые преимущества применения вилдаглиптина в комбинации с меторормином в улучшении гликемического контроля, независимо от исходного уровня гликозилированного гемоглобина (НьА1с), возраста или индекса массы тела (ИМТ) по сравнению с другими ингибиторами дипептидилпептидазы-4 (иДПП4); Комбинированная терапия с использованием 50 мг вилдаглиптина и метформина два раза в день значительно снижала средний исходный уровень НьА1с (от -0,7 до -0,9\%) и уровни глюкозы крови натощак (-1,4 против 0,1 ммоль/л) по сравнению с плацебо, а также с другими иДПП4; также данная комбинация приводила к наибольшему приросту QALYs $(0,18$ на протяжении продолжительности жизни) среди иДПП-4, в сравнении с лечением комбинацией метформина и глимепирида.

Заключение: Таким образом, комбинация метформин и вилдаглиптин дает преимущества по эффективности и дополнительными механизмами действия, поскольку она не увеличивает риск гипогликемии и не способствует увеличению веса.

Ключевые слова: сахарный диабет 2 типа (СД2Т), ингибиторы дипептидилпептидазы-4 (иДПП-4), эффективность, безопасность

\section{Введение}

Согласно данным Всемирной Организации Здравоохранения в настоящее время сахарный диабет (далее - СД) во всём мире представляет собой важнейшую проблему, число людей с диабетом возросло с 108 миллионов в 1980 году до 422 миллионов в 2014 году [1], при этом более 77\% больных СД проживают в странах с низким и средним уровнем дохода, здесь же отмечается и максимальный прирост уровня заболеваемости. Глобальная распространенность диабета среди взрослых старше 18 лет выросла с 4,7\% в 1980 году до 8,5\% в 2014 году, в 2015 году примерно 1,6 миллиона смертей были непосредственно вызваны диабетом. По прогнозу, число больных СД в мире вырастет до 642 млн. человек в 2040 г [2]. Это связано с ростом и старением популяции и увеличением распространенности ожирения, неправильного питания и малоподвижного образа жизни.

В докладе Международной Диабетической Федерации (далее - МДФ) 2011 года показано, что процент роста диабета увеличивается более, чем на $5 \%$ в каждом регионе мира, в особенности Ближнем Востоке и Северной Африке [3].

Наибольшие опасения вызывает то, что СД характеризуется стертой клинической симптоматикой или ее отсутствием на начальных этапах, поэтому приблизительно у 46\% больных факт заболевания долгое время остается неустановленным. Примерно 179 млн. пациентов в мире даже не подозревают, что страдают столь тяжелым недугом, а, значит, не предпринимают мер, позволяющих контролировать гликемию и на момент постановки диагноза уже имеют тяжелые, зачастую необратимые, осложнения. Учитывая, что наибольшее количество больных - это люди трудоспособного возраста и половина из них не доживает до 60 лет, ущерб от данного заболевания расценивается, как катастрофический. В масштабах мирового здравоохранения, лечение СД потребовало в 2016 около 612 млрд. долларов США [4], что составляет примерно $11 \%$ от общего объема расходов здравоохранения на взрослых. СД стал причиной 4,9 млн смертей в 2014 году. По прогнозам ВОЗ, в 2030 году диабет станет седьмой по значимости причиной смерти [1].

В Казахстане диабет также является чрезвычайно актуальной проблемой, влияющей на здоровье нации. По данным Национального регистра по СД, в Республике Казахстан почти 300 тысяч больных, стоящих на учете, из них 95\% - лица с сахарным диабетом 2 типа. Женщин среди больных в 1,7 раза больше, чем мужчин. Ежегодно количество больных увеличивается примерно на 3-4\%. При этом отмечается постоянная тенденция к нарастанию количества больных.

Экспертная оценка распространённости этого заболевания позволяет считать, что к 2040 г. общее число больных составит не менее 642 млн. человек, причём 8791\% из них составят больные СД2Т [2].

С СД также связаны и значительные дополнительные расходы, которые могут существенно превышать расходы на медицинский уход [5]. СД вызывает значительное снижение общей трудоспособности населения, увеличивается число пропущенных рабочих дней (в связи со стационарным или амбулаторным лечением). У части пациентов с диабетом болезнь иногда приводит к инвалидизации.

В последние годы целым рядом исследователей было продемонстрировано, что при ранней интенсивной терапии улучшается прогноз для пациентов с СД, т.к. замедляется процесс развития осложнений [6]. При более эффективной терапии на начальной стадии диабета отмечается увеличение расходов именно на этой стадии, при этом происходит снижение расходов в отдалённом периоде за счёт предотвращения госпитализаций, связанных с осложнениями. Лечение СД2Т у пациентов высокого риска требует стратегии достижения целей гликемии и коррекции факторов риска. У пациентов с небольшой длительностью заболевания предпочтительнее использовать препараты, которые не истощают, а, наоборот, оказывают протективный эффект на функцию $\beta$-клеток поджелудочной железы [7]. В 
этой связи комбинация хорошо известного метформина с препаратами группы ингибиторов дипептидилпептидазы-4 (далее - иДПП-4) обладает привлекательной перспективой.

Таким образом, социально-экономическое бремя СД2Т, обусловленное широкой распространенностью заболевания и высоким риском серьезных осложнений, приводящие к инвалидизации и смертности, в т. ч. среди трудоспособного населения очень велико, в связи, c чем проведение исследований, направленных на клинико-экономическую оценку эффективности новых препаратов, а в частности применение вилдаглиптина при неудовлетворительном гликемическом контроле на фоне монотерапии метформином является актуальной задачей системы здравоохранения [8,9].

\section{Материалы и методы}

В результате поиска в международных базах данных PubMed/Medline, Ovid, DARE, Cochrane Central Register of Controlled Trials и «серой» литературе было обнаружено 280 публикаций. Поиск осуществлялся с помощью ограничительных фильтров: публикация с 2013 по 2017 гг., только на английском языке, проведенные на человеке, имеющие дизайн критических обзоров, систематических обзоров, рандомизированных контролируемых исследований (далее-РКИ), мета-анализов. Критерии включения для исследовательских вопросов были разработаны в соответствии с методикой РІСО. В итоговый анализ вошли 22 полнотекстовых исследования.

Оценка затрат на оказание медицинской помощи проводилась на основе Приказа Министра здравоохранения и социального развития Республики Казахстан от 16 сентября 2015 года № 725 «Об утверждении тарифов на медицинские услуги в рамках гарантированного объема бесплатной медицинской помощи» (с изменениями и дополнениями по состоянию на 15.08.2017 г.) и клинических протоколов диагностики и лечения (одобренных протокольным решением Объединенной комиссии по качеству медицинских услуг Министерства здравоохранения Республики Казахстан от «10» ноября 2017 года №32) [10, 11].

Bce расчёты выполнены в соответствии с зарегистрированными в Республике Казахстан ценами в тенге за 2017 г. [10].

В качестве основных источников данных по эффективности использовались результаты обнаруженных исследований и мета-анализов, а также официальная статистическая информация Агентства Республики Казахстан по статистике [12], данные Электронного регистра диспансерных больных и Электронного регистра стационарных больных.
Были определены используемые в клинической практике Казахстана препараты, их лекарственные формы и режимы, а также цены для проведения анализа. Проведен анализ статуса каждого из препаратов СД2Т, применяемых в Республике Казахстан.

Для оценки влияния рассмотренных схем лечения на качество жизни использовали показатель QALY. Поскольку в Казахстане нет данных для определения влияния диабета и его осложнений на качество жизни, базовый показатель QALY (показатель для пациентов с диабетом без каких-либо осложнений) был смоделирован с использованием среднего значения показателя качества жизни, о котором сообщается в анализе данных о качестве жизни из UKPDS [13]. Снижение показателя, связанный с осложнениями, также применялись и были взяты из исследования UKPDS 62, за исключением почечной недостаточности [14], гипогликемии [15] и увеличения веса [16].

В качестве показателя безопасности оценивали число фиксированных эпизодов гипогликемии, включая тяжелую гипогликемию. В ходе анализа затрат на гипогликемии, c учетом особенностей оказания медицинской помощи в Казахстане, предполагалась равная стоимость каждого гипогликемического эпизода, включавшая в себя вызов бригады скорой медицинской помощи, без необходимости госпитализации, при тяжелой гипогликемии с необходимостью госпитализации.

Основными результатами экономического анализа были затраты и QALYs, на основе которых был проведен анализ «затраты-эффективность» проводился в соответствии общепринятыми рекомендациями [17]. В качестве основного критерия компенсации использовалось снижение уровня гликозилированного гемоглобина $(\Delta$ $\mathrm{HbA} 1 \mathrm{C}, \%)$, с определением коэффициента неудачной терапии. Оценивалось влияние изменения уровня $\mathrm{HbA1c, \%}$ на частоту развития микрососудистых и макрососудистых осложнений СД 2 типа. На заключительном этапе оценки полезности сравниваемых схем терапии проводился расчёт дополнительных лет жизни с поправкой на качество за весь период моделирования с учётом влияния осложнений СД 2 типа и их последствий.

\section{Результаты}

Нами было проанализировано 6 схем лечения (метформин + глимепирид, метформин + вилдаглиптин, метформин + алоглиптин, метформин + линаглиптин, метформин + саксаглиптин, метформин + ситаглиптин) и были обнаружены основные утилиты эффективности и безопасности из международных публикаций (Таблица 1).

Таблица 1 Основные утилиты эффективности и безопасности моделируемых вмешательств

\begin{tabular}{|l|l|l|l|l|l|l|}
\hline Параметр & $\begin{array}{l}\text { Метформин } \\
+\end{array}$ & $\begin{array}{l}\text { Метформин } \\
+\end{array}$ & $\begin{array}{l}\text { Метформин } \\
+\end{array}$ & $\begin{array}{l}\text { Метформин } \\
+ \text { глимепирид } \\
\text { вилдаглиптин }\end{array}$ & $\begin{array}{l}\text { Метформин } \\
+ \\
\text { саксаглиптин }\end{array}$ & $\begin{array}{l}\text { Метформин } \\
+ \\
\text { ситаглиптин }\end{array}$ \\
\hline Снижение НьА1с, первый год (\%) & $-0,53$ & $-0,44$ & $-0,41$ & $-0,30$ & $-0,37$ & $-0,40$ \\
\hline $\begin{array}{l}\text { Коэффициент неудачной } \\
\text { терапин* (\%) }\end{array}$ & 0,37 & 0,20 & 0,22 & 0,29 & 0,23 & 0,28 \\
\hline Гипогликемия (\%) & 16,2 & 1,7 & 1,3 & 4,7 & 1,7 & 4,5 \\
\hline Тяжелая гипогликемия (\%) & 0,72 & 0 & 0 & 0 & 0 & 0 \\
\hline Увеличение веса (кг/год) & 1,56 & $-0,23$ & $-0,42$ & $-0,15$ & $-1,10$ & $-1,07$ \\
\hline Источники & {$[21]$} & {$[22]$} & {$[23]$} & {$[19]$} & {$[20]$} & {$[21]$} \\
\hline $\begin{array}{l}\text { Изменение соотношения } \\
\text { холестерина и ЛПВП (\%/год) }\end{array}$ & $-2,37$ & $-5,18$ & $-5,21$ & $-4,59$ & $-5,12$ & $-4,72$ \\
\hline Источники & {$[24]$} & {$[24]$} & {$[24]$} & {$[24]$} & {$[24]$} & {$[24]$} \\
\hline
\end{tabular}


По данным исследований, базовый показатель и показатели снижения QALY для каждого из различных осложнений пациента с СД2Т составили: никаких осложнений: 0,780, ишемическая болезнь сердца: -0,090, инфаркт миокарда (нефатальный): $-0,055$, застойная сердечная недостаточность: -0,108, инсульт (нефатальный): $-0,164$, ампутация нижних конечностей: $-0,280$, слепота в одном глазу: -0.07426, почечная недостаточность: -0,37927, гипогликемия: $-0,014$, тяжелая гипогликемия: $-0,047$ и прирост массы тела (на единицу прироста в ИМТ): -0,005.
Результаты исследования UKPDS 62 были использованы для прогнозирования микрососудистых и макрососудистых осложнений и смертности (как от СД2Т, так и всех причин) в течение горизонта продолжительностью жизни, взятого за 40 лет. Модель симулировала когорту из 10000 пациентов в годовых циклах, что позволило надежно оценить ожидаемые затраты и выгоды и было адаптировано для анализа увеличения веса и гипогликемических событий, специфичных для каждой схемы. Обзор имитационной модели пациента представлен на Рисунке 1.

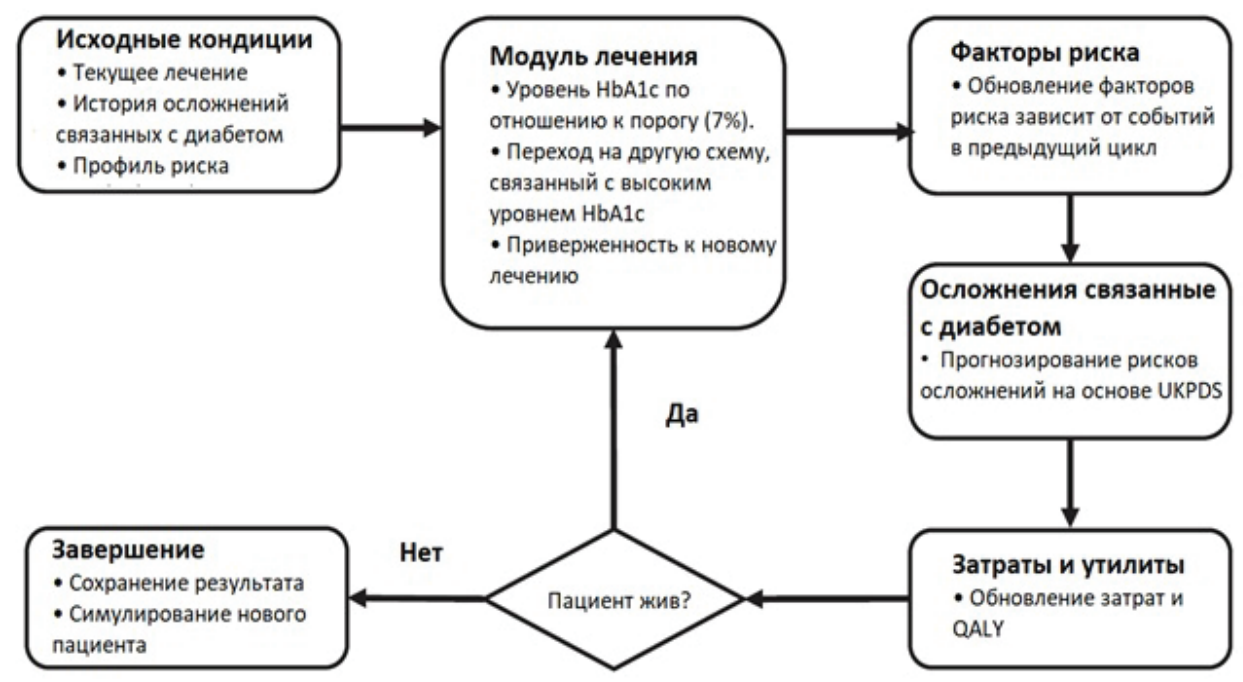

Рисунок 1 - Обзор имитационной модели пациента

В каждом последующем цикле пациенты могли иметь одно из следующих осложнений, связанных с диабетом, в зависимости от их профиля риска: ишемическая болезнь сердца, инфаркт миокарда, хроническая сердечная недостаточность, почечная недостаточность, инсульт, ампутация нижней конечности или слепота в одном глазу. Учитывается понижающее влияние ингибиторов ДПП-4 в комбинации с метформином на соотношение общего уровня холестерина и липопротеидов высокой плотности для пациентов, более низкий коэффициент неудачной терапии, большая степень снижения НbA1c до целевого уровня, чем комбинации глимепирида и метформина (Таблица 2), что способствовало более частому переключению пациентов с СД2Т, получавшим метформин плюс глимепирид, к терапии на основе инсулина. Пациенты переходили на терапию инсулином в течение в среднем 5 лет при терапии метформином плюс ингибиторы ДПП4 и 4 лет при терапии метформином и глимепиридом, соответственно. В течение 5 лет моделирования отмечалась довольно высокая пропорциональная разница в распространении диабетических осложнений между пациентами, получавшими комбинацию метформина/ ингибиторов ДПП-4 и комбинацию метформина/ глимепирида, которая была заметно больше по сравнению с разницей в распространении диабетических осложнений на протяжении продолжительности жизни.

Таблица 2 Затраты на осложнения, связанные с лечением СД2Т

\begin{tabular}{|c|c|c|c|}
\hline \multirow[t]{2}{*}{ Осложнение } & \multicolumn{2}{|c|}{ Затраты на осложнения (тнг) } & \multirow[t]{2}{*}{ Источник } \\
\hline & 1-й год & Последующие & \\
\hline \multicolumn{4}{|l|}{ (в год) } \\
\hline Ишемическая болезнь сердца & 85725,18 & $720,66^{*}$ & [38] \\
\hline Инфаркт миокарда (нефатальный) & 234190,96 & $865,64^{*}$ & [38] \\
\hline Хроническая сердечная нежостаточность & 91109,22 & $1484,81^{*}$ & [38] \\
\hline Инсульт (нефатальный) & 232532,79 & $1177,34^{*}$ & [38] \\
\hline Ампутация нижних конечностей & 581331,98 & $2342,45^{*}$ & $\begin{array}{l}\text { Расчетные затраты с учетом вероятности применения } \\
\text { тромболитических препаратов }\end{array}$ \\
\hline Слепота (1 глаз) & 907838,20 & 907838,20 & $\begin{array}{l}\text { Расчетные затраты с учетом вероятности применения } \\
\text { тромболитических препаратов }\end{array}$ \\
\hline Почечная недостаточность & 1257952,80 & 1257952,80 & $\begin{array}{l}\text { Расчетные затраты с учетом вероятности применения } \\
\text { тромболитических препаратов }\end{array}$ \\
\hline Гипогликемия & 18264,41 & - & $\begin{array}{l}\text { Расчетные затраты с учетом вероятности применения } \\
\text { тромболитических препаратов }\end{array}$ \\
\hline Тяжелая гипогликемия & 67445,40 & - & [38] \\
\hline Инфаркт миокарда (фатальный) & 310503,94 & - & $\begin{array}{l}\text { Расчетные затраты с учетом вероятности применения } \\
\text { тромболитических препаратов }\end{array}$ \\
\hline Инсульт (фатальный) & 284681,05 & - & $\begin{array}{l}\text { Расчетные затраты с учетом вероятности применения } \\
\text { тромболитических препаратов }\end{array}$ \\
\hline
\end{tabular}


Среди ингибиторов ДПП-4 наименьшие показатели частоты как макро- и микрососудистых осложнений отмечались для комбинации метформина и вилдаглиптина. Показатель смертности в течении 5 лет моделирования, который включал в себя как смертельные случаи, связанные с диабетом, так и не связанные с диабетом, также был наименьшим для данной комбинации.

\section{Обсуждение}

Одним из важных различий сравниваемых стратегий являлась вероятность развития гипогликемии и тяжелой гипогликемии. Более высокая частота гипогликемии, в том числе тяжелых гипогликемий, приводила к увеличению стоимости лечения гипогликемий на одного пациента для стратегии метформин плюс глимепирид по сравнению со стратегией метформин плюс ингибиторы ДПП-4, причем наименьший риск развития гипогликемии был характерен для комбинаций метформина с алоглиптином, вилдаглиптином и саксаглиптином.

Более высокий коэффициент неудачной терапии при применении комбинации метформина и глимепирида, в течение горизонта на протяжении продолжительности жизни, чаще приводил к необходимости изменения терапии СД2Т, включая подключение инсулина, что приводило к увеличению затрат. Добавление ингибиторов ДПП-4 к метформину, по сравнению с добавлением глимепирида к метформину, приводило к увеличению затрат на лекарственные средства, использованные на одного пациента, но одновременно с этим снижались затраты на коррекцию побочных эффектов, связанных с проводимым лечением на одного пациента.

Вместе с тем, затраты на лекарственные средства в течение горизонта на протяжении продолжительности жизни, связанные с применением комбинации ингибиторов ДПП-4 и метформина значительно варьировали внутри группы, и составили 5170810 тг для вилдаглиптина, 5858 313 тг для алоглиптина, 6256385 тг для линаглиптина, 7264 316 тг ситаглиптина, 7272809 тг для саксаглиптина.

В связи с меньшей вероятностью макро- и микрососудистых осложнений при применении комбинации метформина и ингибиторов ДПП-4, уменьшались затраты на лечение осложнений СД 2 типа. В связи с наиболее низкой частотой макро- и микрососудистых осложнений, присущей терапии метформин плюс вилдаглиптин, для данной стратегии уровень затрат на лечение осложнений СД 2 типа был наиболее низким.

Стратегия применения комбинации метформина и ингибиторов ДПП-4 способствовала приросту дополнительных лет жизни с поправкой на качество за весь период моделирования. Лечение комбинацией вилдаглиптина и метформина приводило к наибольшему приросту QALYs (0,18 на протяжении продолжительности жизни) среди ингибиторов ДПП-4, в сравнении с лечением комбинацией метформина и глимепирида.

Несмотря на некоторое увеличение общих затрат на одного пациента, связанного с применением стратегии метформин плюс вилдаглиптин в сравнении со стратегией метформин плюс глимеперид (15 978586 тг и 15591522 тг, соответственно), данная стратегия продемонстрировала наибольшую затратную эффективность с ICER 2150 355,19 тг за QALY. Для сравнения показатель затратной эффективности для комбинации метформина и алоглиптина, был хуже в 3,4 раза, для терапии метформином и ситаглиптином - в 9,2 раза хуже, метформин плюс линаглиптин - в 9,6 раз, а метформин плюс саксаглиптин в 10,9 раз хуже.

Анализ проведенных исследований с целью оценки переносимости/безопасности и эффективности ингибиторов ДПП-4, а именно вилдаглиптина, в комбинации с метформином у взрослых пациентов свидетельствуют об улучшении гликемического контроля, независимо от исходного уровня НbA1c, возраста или ИМТ; а также демонстрируют наименьшие показатели частоты как макро- так и микрососудистых осложнений. Кроме того, вилдаглиптин увеличивает чувствительность $\beta$-клеток поджелудочной железы к глюкозе, функции $\alpha$-клеток и чувствительность к инсулину; уменьшает липемию, предположительно ингибируя абсорбцию жира и уменьшая запасы триглицеридов в тканях. Эти эффекты приводят к повышению толерантности к глюкозе и снижению уровня глюкозы крови натощак. А также стало известно, что вилдаглиптин в комбинации с метформином имеет большее преимущество, по сравнению с используемыми в настоящее время комбинациями лекарственных средств, эффективностью и дополнительными механизмами действия, поскольку она не способствует гипогликемии и увеличению веса. Так, комбинированная терапия с использованием 50 мг вилдаглиптина и метформина два раза в день значительно снижала средний исходный уровень HbA1c (от $-0,7$ до $-0,9 \%$ ) и уровни глюкозы крови натощак (-1,4 против 0,1 ммоль/л) по сравнению с плацебо. Немаловажно отметить хорошие результаты при назначении вилдаглиптина пожилым пациентам старше 75 лет, имеющим умеренную или тяжелую форму почечной недостаточности.

Среди всех и-ДПП4 вилдаглиптин является самым эффективным в плане снижения уровня гликозилированного гемоглобина и постпрандиальной гликемии.

Стратегия применения метформина и вилдаглиптина, обладает наилучшими показателями затратной эффективности в сравнении со стратегией применения метформина и глимепирида и метформина и других и-ДПП4, с позиций системы здравоохранения Республики Казахстан, в течение горизонта на протяжении продолжительности жизни, обладая оптимальным профилем клинической эффективности и безопасности.

\section{Выводы}

Таким образом, комбинация метформин и вилдаглиптин дает преимущества по эффективности и дополнительными механизмами действия у взрослых пациентов с сахарным диабетом 2 типа при неудовлетворительном гликемическом контроле.

Disclosures: There is no conflict of interest for all authors. 


\section{Литература}

1. World Health Organization. Media Centre. Diabetes (Fact sheet no. 312. [Cited on: 31 January 2018] Available at: http://www. who.int/mediacentre/factsheets/ fs $312 / \mathrm{en} /$

2. Ogurtsova K., da Rocha Fernandes J. D., Huang Y., et al. Global estimates for the prevalence of diabetes for 2015 and 2040. Diabetes Research and Clinical Practice. 2017; 128:40-50. https://doi.org/10.1016/j.diabres.2017.03.024

3. Online version of IDF Diabetes Atlas. International Diabetes Federation 2013.www.idf.org/ diabetes atlas. Last Accessed July 2014., доступно на сайтеhttps://www.diapedia.org/

4. World Health Organization. Global report on diabetes. Geneva: 2016.- $88 \mathrm{p}$

5. Dall T.M. et al. The economic burden of elevated blood glucose levels in 2012: diagnosed and undiagnosed diabetes, gestational diabetes mellitus, and prediabetes. Diabetes Care. 2014; 37(12):3172-3179. https://doi.org/10.2337/dc14-1036

6. UK Prospective Diabetes Study (UKPDS) Group Intensive blood-glucose control with sulphonylureas or insulin compared with conventional treatment and risk of complications in patients with type2 diabetes (UKPDS 33). Lancet. 1998; 352(9131):837-853. https://doi.org/10.1016/S0140-6736(98)07019-6

7. Ashcroft FM, Rorsman P. Diabetes mellitus and the beta cell: the last ten years. Cell. 2012; 148(6):1160-1171. https://doi. org/10.1016/j.cell.2012.02.010

8. Bhutani J, Bhutani S. Worldwide burden of diabetes. Indian Journal of Endocrinology and Metabolism. 2014; 18(6):868-870. https://doi.org/10.4103/2230-8210.141388

9. UK Prospective Diabetes Study (UKPDS) Group Intensive blood-glucose control with sulphonylureas or insulin compared with conventional treatment and risk of complications in patients with type2 diabetes (UKPDS 33). Lancet. 1998; 352(9131):837-853. https://doi.org/10.1016/S0140-6736(98)07019-6

10. Prikaz Ministra zdravookhraneniya i sotsial’nogo razvitiya Respubliki Kazakhstan ot 16 sentyabrya 2015 goda № 725 «Ob utverzhdenii tarifov na meditsinskiye uslugi v ramkakh garantirovannogo ob»yema besplatnoy meditsinskoy pomoshchi» (s izmeneniyami i dopolneniyami po sostoyaniyu na 15.08 .2017 g.) i klinicheskikh protokolov diagnostiki i lecheniya (odobrennykh protokol'nym resheniyem Ob»yedinennoy komissii po kachestvu meditsinskikh uslug Ministerstva zdravookhraneniya Respubliki Kazakhstan ot «10» noyabrya 2017 goda №32)

11. Tarify na meditsinskiye uslugi v ramkakh garantirovannogo ob»yema besplatnoy meditsinskoy pomoshchi utverzhdennyye Prikazom Ministra zdravookhraneniya i sotsial’nogo razvitiya Respubliki Kazakhstan ot 16 sentyabrya 2015 goda № 725 (s izmeneniyami i dopolneniyami po sostoyaniyu na $15.08 .2017 \mathrm{~g}$.)

12. Ministerstvo natsional'noy ekonomiki Respubliki Kazakhstan. Komitet po statistike. Dinamika osnovnykh sotsial'noekonomicheskikh pokazateley. Available at: www.stat.gov.kz

13. Clarke P., Gray A., Holman R. Estimating utility values for health states of type 2 diabetic patients using the EQ-5D (UKPDS 62). Med. Decis. Making. 2002; 22(4):340-349. https://doi.org/10.1177/027298902400448902

14. Manns B, Meltzer D, Taub K, et al. Illustrating the impact of including future costs in economic evaluations: an application to end-stage renal disease care. Health Econ. 2003; 12:949-58. https://doi.org/10.1002/hec.790

15. Currie CJ, Morgan CL, Poole CD, et al. Multivariate models of health-related utility and the fear of hypoglycaemia in people with diabetes. Curr Med ResOpin. 2006; 22:1523-34. https://doi.org/10.1185/030079906X115757

16. Erhardt W, Bergenheim K, Duprat-Lomon I, et al. Cost effectiveness of saxagliptin and metformin versus sulfonylurea and metformin in the treatment of type 2 diabetes mellitus in Germany: a Cardiff diabetes model analysis. Clin Drug Investig. 2012; 32:189-202. https://doi.org/10.2165/11597060-000000000-00000

17. Drummond MF, Sculpher MJ, Claxton K, Stoddart GL, Torrance GW Methods for the Economic Evaluation of Health Care Programmes. Oxford University Press. 2015; (4)455.

How to cite this article: Alima Almadiyeva, Zhanay Akanov, Venera Almatova, Karlygash Absattarova. Systematic review of clinical and economic effectiveness of vildagliptin in type 2 diabetic patients with poor glycemic control on monotherapy with metformin [in Russian]. J Clin Med Kaz. 2018; 4(50):34-39 